\title{
EL PERSONAJE DE ANTÍGONA EN EDIPO EN COLONO DE SÓFOCLES
}

\author{
MARÍA INÉS SARAVIA DE GROSSI \\ Centro de Estudios Helénicos \\ Universidad Nacional de La Plata (Argentina)
}

\begin{abstract}
Resumen: En Edipo en Colono de Sófocles, Antígona personifica la voz de moderación que se opone a Creonte y Polinices. Ella representa el principio ético de filía, que definimos desde tres aspectos. El primero, como los lazos de amistad o de afinidad concernientes a los lazos familiares. El segundo, como la relación que existe con los ciudadanos con quienes se supone que uno tiene intereses en común, dicha actitud se halla cercana a la filantropía. La tercera acepción quizás interpreta más aproximadamente el concepto moderno de "amigo". Para concluir, el carácter conciliador de la joven hija de Edipo recuerda algunas actuaciones de la vejez honorable de la épica homérica.
\end{abstract}

Palabras clave: Sófocles, Edipo en Colono, Antígona, filía, conceptos vinculados.

En el presente estudio se pone énfasis en la caracterización de Antígona en

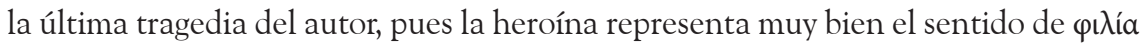
y, a propósito de este concepto, se indaga acerca de qué expone Sófocles cuando somete a consideración la disyuntiva de "amigos o enemigos". ${ }^{1}$ La complejidad de los lazos de amistad y familiares en el mito de los Labdácidas se vuelve una manera de promover la reflexión en la audiencia de Sófocles que integra la socie-

1 Una primera versión de este trabajo fue leída en las VIII Jornadas de Investigación en Filosofía de Profesores, Graduados y Alumnos, organizadas por el Departamento de Filosofía de la Facultad de Humanidades y Ciencias de la Educación de la Universidad Nacional de La Plata, en abril de 2011. La versión definitiva fue brindada como conferencia en las VII Jornadas de Literatura Griega Clásica, organizadas por el Centro de Estudios Helénicos de la Facultad de Humanidades y Ciencias de la Educación, IdIHCS, UNLP, en junio de 2011 en La Plata. 
dad ateniense. El hecho de repasar el concepto permite visualizar las condiciones histórico-sociales que vivían en aquel momento los ciudadanos.

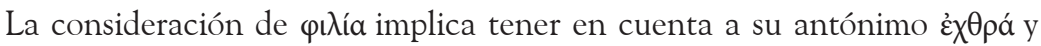
analizar las implicancias que la polarización conceptual aporta. La ética homérica se sustentaba, precisamente, en la sentencia "Amar a los amigos, odiar a los enemigos", como una variante de la ley del talión.

El segundo término de la oposición implica una violación de $\varphi$ ìía, que desvincula a los seres humanos de todo contexto. Esta situación suele darse en los reconocimientos trágicos, dado que se produce la ruptura con lo que había, para luego comenzar de otra manera, con otras alternativas y, asimismo, la disyuntiva se pone de relieve en situaciones de enfrentamientos bélicos.

La dicotomía se vuelve confusa en las últimas obras de Sófocles, en las cuales no se sabe con exactitud -y el autor quiere que así ocurra- quiénes forman el grupo de amigos o de enemigos. De semejante dilema surge el espacio reflexivo sobre el comportamiento de los seres humanos en una coyuntura determinada.

Ф\入ía requiere una ayuda y beneficios recíprocos (Blundell, 1989, p. 32), tales como vigor, salud, y poder, cada una de ellas confluye en condiciones placenteras para el receptor. Generalmente se expresan en términos de preservación

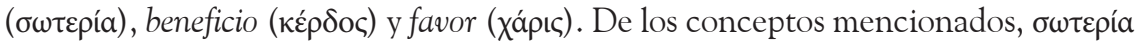

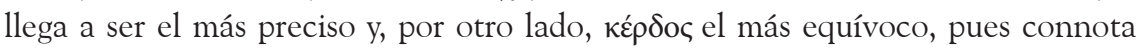
el propio interés del agente y da como resultado una actitud potencialmente vergonzante. La amistad supone un sustrato de sinceridad y tolerancia que se quiebra, cuando existen ofensas o acusaciones.

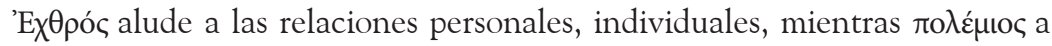
los enemigos de guerra; el fundamento ético de $\varphi \imath \lambda i ́ a$ se cimienta en promover el bien en los otros.

Si se profundiza el enfoque en el adjetivo píloc, se observan tres líneas de sentidos:

- En primer lugar, el concepto compone lazos de amistad o de afinidad en relación a los vínculos familiares.

- El segundo sentido alude a la relación que existe con los ciudadanos, con quienes se supone que uno tiene intereses en común. Esta actitud se halla cercana a la filantropía. En el contexto de la ciudad existen muchísimos lazos de $\varphi \imath \lambda i ́ a$, por lo tanto el exilio puede ser identificado como una carencia de amigos, y eso lo convierte en un castigo peor que 
la muerte misma. De hecho ónóvora "concordia" ha quedado identificada

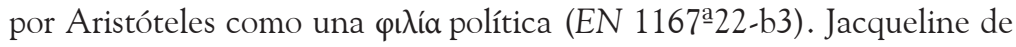
Romilly (2006) se ha explayado sobre este tema. La autora sostiene que el concepto se logra cuando la pluralidad de voces es escuchada y obtiene su espacio en la sociedad. El término ópóvora se apoya en el de amistad, que no sólo implica tolerancia, sino que supone -o da por sentado- la aceptación del otro, la conciencia de aquello que se vuelve común entre quienes viven juntos. Si no se ejercitan habitualmente estos sentimientos sociales de respeto a la diversidad, sobreviene la guerra civil o ớ́oıç. Para la autora francesa, ser civilizado requiere resistir a la violencia en aras de la homonoia. Ese ha llegado a ser el desafío en la antigüedad y sigue siéndolo en nuestros días.

- El último aspecto, el tercero, quizás interpreta más aproximadamente el concepto moderno de 'amigo'. Este tipo de pí̉os puede superponerse con los anteriores. Además, el matrimonio constituye un caso especial de $\varphi$ ı $\lambda$ ía, establecido a través de ofrecimientos y de retribuciones de favores. Otro caso también en el que se halla implicado el concepto de $\varphi$ í̉oc ocurre en la amistad entre los mortales y los dioses.

Belfiore (2000) afirma que en las tragedias se tergiversa o se quebranta la dicotomía y la máxima que resume la ética homérica que mencionamos. En suma, se interrumpen los códigos de la reciprocidad. ${ }^{2}$ Esa relación enfermiza o anormal desencadena el efecto trágico en las obras.

El presente estudio propone una indagación acerca de la búsqueda de filía en el personaje de Antígona en Edipo en Colono de Sófocles. Además de la función de lazarillo, Antígona representa la voz de moderación que parece desdibujarse en el primer plano de la acción bélica masculina, es decir, frente a Creonte y Polinices en el centro de la obra, fuertemente argumentativo.

En el Prólogo se produce una suerte de reconocimiento del lugar y también un reconocimiento personal. A continuación, la Párodos commática prosigue este reconocimiento con connotaciones más sociales, dadas por ejemplo con palabras como aì́ws.

Antes del rapto que tiene lugar en el Estásimo II, en el Episodio correspondiente (827-28 y 844) Antígona vive momentos de angustia extrema, y esa desa-

2 Cfr. Seaford (1994, passim). 
parición física que sufren, considerada como la escena más violenta en tragedia, ${ }^{3}$ podría pensarse como un descenso del héroe, según el canon épico, ya que la joven Antígona adquiere un estatuto de personaje de heroína silenciosa, abnegada y firme en sus convicciones. Podría haber ocurrido que Antígona como Ismene, víctimas de la violencia, mostraran todo su rencor o disconformidad, pero en las siguientes intervenciones se observa una joven que no ejerce el resentimiento sino la

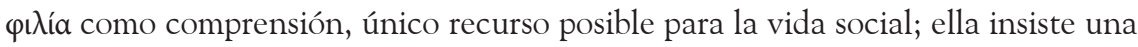
y otra vez en el poder de la palabra como Néstor en Ilíada y Filoctetes en las obra homónima de Sófocles. Sin duda se produjo un cambio sustantivo en su interioridad: se retira desesperada y regresa a escena como una personalidad equilibrada mental y emotivamente.

En el Episodio III -a modo de un nuevo prólogo- Antígona se muestra como una guía no sólo física sino espiritual para su padre. A su vez, en el Estásimo III, a modo de un nuevo Párodos, los ancianos cantan los pesares de la vejez y lo más doloroso se vuelve reconocer que viven exentos de $\varphi \imath \lambda i^{\prime}{ }^{4}{ }^{4}$ Luego en el commós del Episodio IV (1447-99) Antígona interviene en trímetros (como también lo hace Edipo), como moderadora, irrumpe en el centro de cada grupo de versos para facilitar la comunicación con el padre. ${ }^{5}$ Finalmente en el Éxodo además del dolor por el anciano mendicante y su abnegación de siempre, sabemos que dará la vida por el hermano cuando decida acompañarlo hasta Tebas, un signo de amor filial único.

Si bien resulta relevante la actuación de la joven en la segunda parte de la obra, su actuación previa en la Párodos ofrece los primeros testimonios de su carácter altruista, pues en efecto interviene como la voz de la humanidad.

Ella ha ofrecido testimonios de su carácter conciliador en la última estrofa de la extensa Párodos commática (237-53), donde clama por piedad y ruega por los

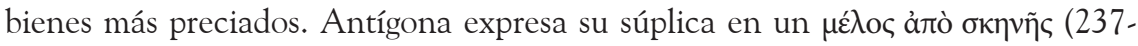
$253)^{6}$ y la intensidad de la escena oscila entre la compasión y el terror religioso que se apodera de los ancianos del Coro, equivalente a la experiencia del Éxodo. An-

3 Cfr. nuestro artículo (2004/5, p. 119-129).

4 El pesimismo por falta de $\varphi$ ìía, que ocasiona la conciencia de la fragilidad del hombre, constituye un motivo típico de la poesía de Simónides y de Mimnervo. Cfr. Di Benedetto (1988, p. 217-247).

5 Cfr. nuestro artículo (2010, p. 97-111).

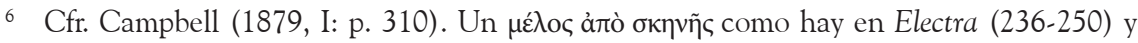
en Filoctetes (1170-1217). No se halla una composición de solo lírico en las obras de la 
tígona ruega por aiঠós para el desterrado (247) y pide piedad para ella y su padre frente a los ancianos que en la Párodos quisieron expulsar a Edipo del altar de las Euménides y, al instante del solo de la joven, ellos se disculpan por su actitud por el temor a los dioses (254-579). Posteriormente con la llegada de Teseo, se mostrarán benevolentes. La hija de Edipo menciona el rechazo que suscitan los actos involuntarios de su padre, por tanto pide que le concedan la gracia de la clemencia por

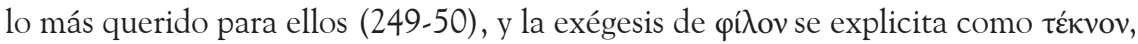

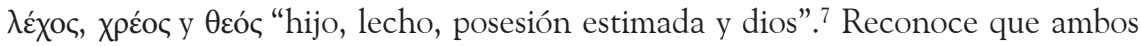
están en manos de los mayores como si aquellos decidieran su destino, tanto como podría resolverlo un dios. ${ }^{8}$

En este canto hay algunas reiteraciones llamativas, en primer lugar el tópico de los ojos: ö $\mu \mu \alpha$ (v. 245). ${ }^{9}$ Antígona pide que la miren a ella que muestra a su padre; él es el ciego, privado de sus ojos, pero ella los representa, realmente formula una manera muy simple de persuadir y buscar la compasión. ${ }^{10}$

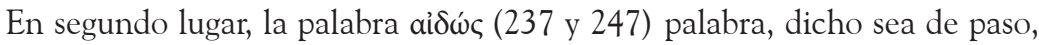
que remite a la psicología homérica, e implica vulnerabilidad, vergüenza, sensibilidad extrema al juicio de los demás, es decir, a la norma ideal que expresa la sociedad. El concepto se halla relacionado con é̉ $\lambda$ eoc ${ }^{11}$ En el primer caso los ancianos son llamados aỉó $\varphi \rho o v \varepsilon \varsigma$, no como un mero epíteto, sino alude al espíritu devoto

primera etapa de Sófocles, es decir, ni en Áyax, Antígona, Traquinias o Edipo Rey. Los diferentes metros líricos favorecen la idea de desasosiego.

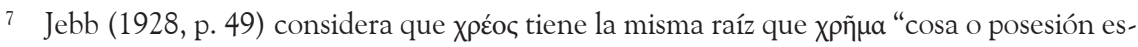
timada”. Campbell lo traduce como "objeto de cuidado" y agrega que la joven se expresa consciente de que la propiedad constituye algo inapreciable para los ancianos.

8 El ejemplo muestra la dificultad que encuentran los personajes de Sófocles, en la última etapa de su creación, en el trato con el prójimo.

9 Como en Agamenón de Esquilo (240-241). Cfr. Benavente Barreda (1999).

10 Cfr. Dain y Mazon (1974, p. 88).

11 Cfr. Errecalde (2000, p. 41-52). Aỉós es un sentimiento provocado por la percepción del propio lugar en la estructura social y de las obligaciones que acompañan esa postura. Para el tema cfr. Cairns (2002, passim), quien afirma que resulta incuestionable considerar el concepto como una emoción. Este implica vergüenza y desconcierto y alude a una conducta regida por el honor: "References to the audience then and metaphors of 'eyes' and 'being seen' indicate the essential role of the detached observer in shame; thus shame does requires the concept of an 'other', but the 'other' may be woolly internalized, such that one can be an observer but not a real or hypothetical external observer, so that the notion of the observer may be at once essential and metaphorical" (p. 18). 
que el coro ha mostrado. ${ }^{12}$ Antígona apela a la sensibilidad piadosa de los ancianos más que a una costumbre religiosa.

Por último, en tercer lugar, la reiteración del verbo ävтoual (243-44, y 250) $)^{13}$ en primera persona del presente de indicativo cuyo significado es "encontrar en batalla" y como segunda acepción se halla próximo al sentido de ảvtiá $\zeta \omega$ "acercarse como suplicante, implorar", tanto en Sófocles como también en Eurípides. Curio-

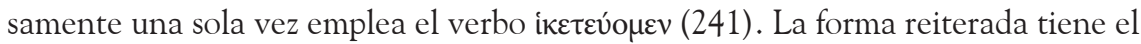
mismo prefijo que el nombre de Antígona, como un juego de coincidencias.

En este final de la Párodos, Antígona señala dos cosas: primero enfatiza todo lo que ha sufrido Edipo, no lo que ha realizado, esto parece dejarlo en el plano de una voluntad ajena a él, por ejemplo, de algún dios. Segundo, corrobora lo expuesto en los tres últimos versos a modo de $\gamma v \omega ́ \mu \eta ~(252-54)$ :

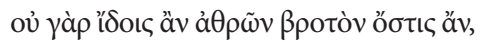

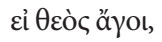

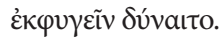

"no podrías conocer, aunque lo busques, a ningún mortal, quienquiera que sea, que, si un dios lo conduce, esté en sus manos evitarlo".

Edipo reitera la palabra uóvoৎ $(261,262,263$ y 265) como para enfatizar el reclamo hacia Atenas, de que lo reciba benevolente. ${ }^{14}$

El Episodio II tan traumático frente a Creón ha, quedado en el pasado, nadie se acuerda ya de la violencia suscitada por el anciano mentiroso. Como ya se ha dicho, el Estásimo II divide la obra en dos instancias. ${ }^{15}$ A partir del regreso de las jóvenes -una escena equivalente al regreso de Edipo a su ciudad natal, como un nuevo Prólogo- ${ }^{16}$ la preocupación que tiene visos de amenaza está supeditada

12 Campbell (1879, I: p. 311) traduce "As you are full of reverence for the Gods, have respect to the suppliant".

13 Sólo se usa en presente e imperfecto. Cfr. Liddell-Scott (1969).

14 Como también ocurre en Heraclidas y Suplicantes de Eurípides: la ayuda que se pide para los indefensos padres de los argivos muertos delante de Tebas.

15 Cfr. mi artículo en Classica 2004/5, p. 119-129.

16 Edipo en Colono insiste con el tópico del vóotoc: vuelven Edipo, las hijas después del rapto perpetrado por Creonte, que también ha llegado desde Tebas y, por último, Polinices en su paso hacia la ciudad que invadirá: Tebas. Asimismo se insiste en el regreso 
al arribo de Polinices con la tropa argiva que espera en las afueras. La expectativa de Antígona y Teseo se sitúa en facilitar el encuentro siguiente entre el padre y el hijo. El lugar de mediador lo cubre la joven.

Es factible dividir el Episodio III, a su vez, en dos partes. La primera consiste en el reencuentro de las hijas con Edipo (1196-1138). En esta instancia Edipo

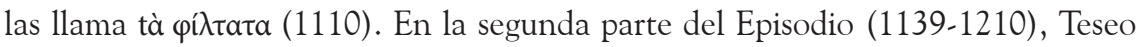
no vuelve sobre los hechos previos inmediatos sino que introduce al hermano de Antígona como un extranjero de Argos, anuncia que se halla frente al altar de Poseidón (1158). Cuando Edipo advierte que se trata de Polinices, lo menciona de la siguiente manera $(1173-74):{ }^{17}$

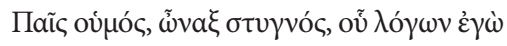

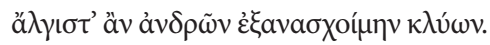

"mi hijo, señor, odiado por mí, cuyas palabras, al escucharlas, yo podría sufrir como las más dolorosas de los hombres".

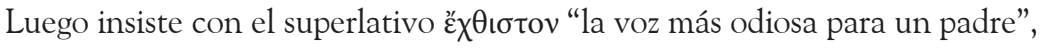
y advierte que no quiere ceder. Teseo intenta persuadirlo y advierte al anciano que Polinices se ha aproximado con una actitud de suplicante $(1158,1165,1179-80)$; de este modo, la secuencia establece el momento preciso en el cual Edipo pasa de ser un suplicante a ser el motivo de la súplica. Ante la negativa del padre, decididamente interviene Antígona, y expresa un discurso de persuasión. ${ }^{18}$ Las dos personas que más han hecho por Edipo piden al anciano que acceda al diálogo. No hay ningún dato textual que indique que Creón fracasó en su tratativa. Resulta llamativo el hiato temporal que se establece entre los dos Episodios. Abruptamente, la primera amenaza quedó superada para siempre. Queda en vilo la segunda, encarnada en Polinices. No obstante, el discurso de Antígona en su totalidad predispone para la

al origen de Edipo, es decir, la tierra. Para esta consideración del mito cfr. Edmunds (1981, p. 221-238), quien confirma que Edipo en Colono asimila a Edipo con el culto a las Erinias-Euménides, debido a la semejanza entre las características de Edipo y las Erinias. Ellas, como divinidades chthónicas, tienen dos funciones opuestas: traen beneficios y asimismo destrucción. Edipo es caracterizado así por Sófocles. En Edipo Rey ha tenido un reinado próspero después de descifrar el enigma de la esfinge pero, de igual forma, se vuelve a la causa de la plaga, el motor contaminante de la ciudad.

17 Para las citas en griego sigo la edición de Pearson (1928). Las traducciones me pertenecen.

18 Prácticamente el único en todo el corpus de Sófocles. 
entrada del hermano, con la esperanza de lograr alguna afinidad entre el padre y el hijo. A continuación, se analizan las palabras de Antígona en el discurso que se extiende entre los versos 1181 y 1203 . En el centro del mismo ella afirma (1191):

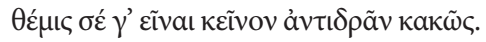

"no es justo que tú devuelvas, a aquel, mal por mal".

Efectivamente, el meollo de las intenciones de Antígona se enfoca en la pacificación de las susceptibilidades, en no promover conductas violentas sino que propicien el diálogo.

De acuerdo con el verso central, como el ejemplo de prudencia o armonía que ella busca restablecer entra las fuerzas en pugna, podemos dividir la argumentación en dos partes equilibradas. La primera ocupa de los versos 1181 hasta el 1190. Los cuatro primeros proclaman un ruego muy efusivo al padre. La joven hija, ya en su obra homónima, decía frente a Creonte que no había venido a este mundo para odiar sino para amar (523). En la última tragedia, propone que Edipo no se guíe por la ley del talión (1189-91).

A poco de comenzar su discurso, Antígona emplea el dual (1184), de este modo incluye a Ismene en su propósito, y se observa una actitud opuesta a las decisiones tomadas en el Prólogo de Antígona. En esta instancia crítica, la joven asegura al padre que Polinices no empleará la violencia (1185).

El discurso de Antígona requiere que el padre ceda, como se les pide a todos los héroes de Sófocles en algún momento de las obras. Exhorta a que Edipo otorgue el permiso para que Polinices acuda a su encuentro, que acepte verlo. Ella insiste en que no hay daño en escuchar (1187); y que por la palabra se traducen los hechos.

Dos vocativos al padre (1181 y 1190) junto con ocho imperativos balizan el texto como un leit motiv que persigue persuadir hacia el ejercicio de la clemencia (1181-1185; 1182-84. 1192, 1195, 1201, en 23 versos).

En esta primera parte se halla la primera de las dos $\gamma v \tilde{\omega} \mu a \mathrm{r}$ o sentencias (1187-88):

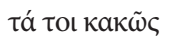

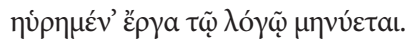

"encontramos que las malas acciones quedan, en efecto, al descubierto en el discurso". 
La segunda $\gamma v \omega ́ \mu \eta(1201-3)$ se halla en el final y ofrece cierto tono esquileo, pero en sentido inverso:

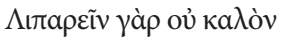

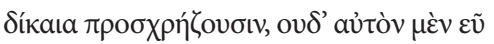

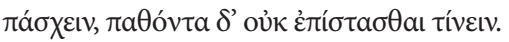

"No está bien que aquellos cuyas demandas

son justas deban suplicar con insistencia, ni tampoco

es justo que alguien reciba un favor y, a su vez, no sepa retribuirlo".

La afirmación, a su vez, equivale a un ruego que no quiere explicitarse, después del imperativo eĩke (1201). Antígona exhorta a que se produzcan acontecimientos simples, decisivos y finales. En el presente, este requerimiento implicaría, en efecto, suscribir el permiso para el arribo de Polinices.

En la segunda parte del discurso (1192-1203), ella requiere que el padre sepa dominar su rencor, porque el resentimiento se torna muy mal consejero (1198), y que él no ha llegado a ser el único que tiene un hijo culpable o problemático. Acentúa el momento de incertidumbre y nerviosismo con el empleo de aliteración con oclusivas (1195-96); la aliteración continúa cuando ejemplifica la injerencia del pasado, en el momento presente, con la pérdida de sus ojos (1200). Ella insiste en que no piense en el ahora sino en todo el sufrimiento pasado, ocasionado por su padre y su madre (1196-97).

En suma, que se ubique como una autoridad respetable, con las responsabilidades hacia los hijos. La concentración en el recuerdo de las experiencias dolorosas del anciano despierta en el espectador, al menos, la imagen de la encrucijada y la muerte de Yocasta. La hija apela al razonamiento del padre (1199) a propósito de la pérdida de luz en los ojos. ${ }^{19}$ Con este requerimiento, Antígona actualiza el momento de reconocimiento en Edipo Rey, cuyo resultado en el presente ha quedado refrendado en la ceguera y el exilio.

Finalmente, el carácter del discurso se observa en las $\gamma v \tilde{\omega} \mu a$, tanto del principio (1187-88) como las dos $\gamma v \tilde{\omega} \mu a$ del final -podríamos afirmar- anti-esquileas:

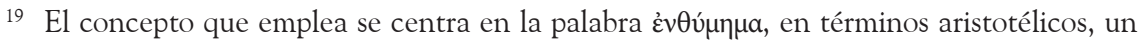
silogismo. Cfr. Ferrater Mora (1992, p. 242-43): “... el hombre en su lenguaje cotidiano tiende a formular razonamientos suprimiendo expresiones que da por entendidas al oyente”. La palabra aparece una vez más (292) en boca del Corifeo, cuando Edipo ha manifestado la involuntariedad de los hechos pasados de su vida. 
la primera se refiere a Teseo y Antígona -en relación a no abusar de quien suplica-; la segunda se refiere a Edipo, y menciona el hecho de no comportarse de acuerdo con las normas de la hospitalidad $(1201,1203) .^{20}$

En el centro (1191) rige el principio ético de Antígona que consiste en no valerse, bajo ningún aspecto, de la venganza. Dos imperativos intensifican el

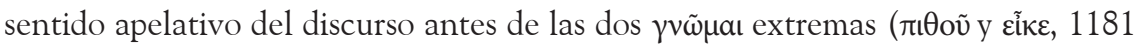
y 1201 respectivamente); en el centro, el imperativo va pospuesto en una oración independiente: $\dot{\alpha} \lambda \lambda^{\prime} \mathfrak{z} \alpha \boldsymbol{v} v v$, junto con el coordinante adversativo y el pronombre expresan literalmente el deseo de Antígona.

Antígona prácticamente concluye el tercer Episodio que ha funcionado como un nuevo Prólogo. Edipo acepta su pedido y la expresión que da cuenta de ello se manifiesta en un oxímoron (1204):

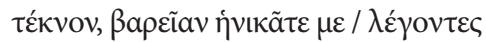

"Hijas, cuando hablan me vencen con un placer opresivo".

En el Episodio IV Antígona anima a Polinices a entablar el diálogo con el padre y lo alienta con el argumento de que las palabras otorgan voz a los que están sin ella (1280-1283) y después del fracaso ante el padre comienza una mini tragedia entre los jóvenes hijos, en donde Antígona adquiere el papel de suplicante,

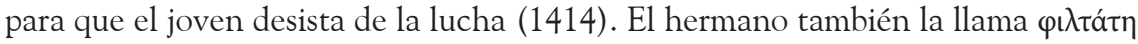
(1416), como Edipo lo ha llamado, a su vez, a Teseo (1169). ${ }^{21}$

La escena adquiere visos de metateatralidad, en el sentido en que en sí misma parece una tragedia en miniatura. Por ejemplo, cuando el diálogo comienza (1399), Polinices tiene conciencia de que ha llegado al fin de su camino, finalizaron sus peripecias, lo que implica que comienza la coyuntura del reconocimiento. Sabe que no puede retroceder ni decir la verdad a la tropa aliada. No hay escapatoria,

20 Hutchinson (1999, p. 47-72, puntualmente 58) estudia las tragedias desde el punto de vista de las acciones imperfectivas y perfectivas, es decir, lo que requiere un desarrollo temporal prolongado y aquello que se muestra como concluido. En Edipo en Colono lo imperfectivo consiste en la etapa de exilio, el sufrimiento prolongado en el tiempo. No obstante, el presente formula una invitación a detener ese movimiento incesante. En el discurso de Antígona, indirectamente, la hija requiere un cambio drástico de actitud, que se produzca la ruptura con el pasado y que se atienda a las palabras del hijo sin prejuicios.

21 A propósito del discurso de Polinices en el Episodio IV (1285-1345) cfr. nuestro artículo (2002, p. 53-69). 
asume su destino y pide que, a su hora, le tributen honras fúnebres (1410). Ante esta situación imprevisible, Antígona decide ir a Tebas $(1744,1770)$ y, con esta resolución, también se asegura su propia muerte.

El diálogo recuerda el encuentro entre Héctor y Polidamas en Ilíada (XVIII: 249-309), cuando este le pide que entren en la ciudad hasta que Aquiles se apacigüe, pero no es oído. La actitud de Héctor resulta semejante a la conducta de Polinices, uno de los tres casos de atasthalía que encontramos en la obra de Sófocles. ${ }^{22}$ El interrogante consiste en dilucidar por qué el joven hijo de Edipo persevera en la guerra si su derrota ha sido anticipada. Suponer que existe una posibilidad para escapar resulta inasequible.

$*$

En el Episodio III -del que ya se ha hablado- y que funciona como escena

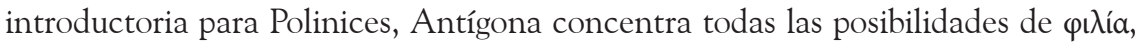
de acuerdo con los principios que se mencionaron. El papel de Antígona se destaca como el personaje mediador, eficaz y modesto. A pesar de su juventud, parece hablar por experiencia, en ese sentido recuerda a Néstor en Ilíada.

La primera intervención decisiva del anciano ocurre en el canto A (247 y ss.), cuando Néstor pasa de lo particular a lo general y clarifica el plan poético, de este modo el tema de la cólera aquilea se inserta en el tema de la guerra de Troya.

Su discurso acentúa cuán indispensable se vuelve cada uno de los héroes para el bien común del ejército. Sus palabras son definidas como (A. 247-49):23

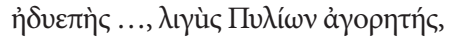

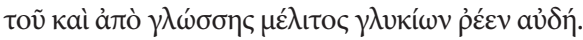

Antígona había expresado por medio de imágenes auditivas el encantamiento que producen las voces con cadencia o consonancia cuando afirmaba en una tercera persona del plural (1192-94):

22 Cfr. nuestro trabajo (2004). Los otros casos se hallan en Antígona (446-47) y Áyax (puntualmente 766-770). Jebb (1899) afirma que el diálogo fraterno ilustra el cariño de Polinices hacia su hermana. Asimismo Saravia (2008, p. 167-182), para otras consideraciones sobre la obra.

23 Para Ilíada seguimos la edición de Monro, David y Allen, Thomas (1920). 


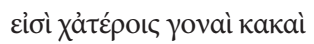

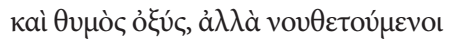

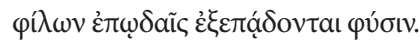

"Otros padres tienen hijos perversos y su corazón es ácido, pero advertidos por las suaves palabras de sus amigos apaciguan su temperamento".

El ejemplo en esa tercera persona del plural otorga la perspectiva necesaria para que Edipo asimile ese ejercicio de indulgencia, al modo del mito de Meleagro en el discurso de Fénix en el canto IX (527-599).

El enunciado de Néstor es desoído por Agamenón, quien no concibe una actitud conciliadora, al menos en estos momentos. El sentido de la disputa entre Agamenón y Aquiles consiste en que, al amenazar con quitar el үépạ de otro, niega totalmente el código de honor de la comunidad guerrera a la que pertenece. Aquiles se opone al Atrida en cuanto el primero se encuentra del lado de los derechos establecidos de los guerreros que integran la sociedad. La respuesta de Aquiles y su intento de mantener el estatuto que ha sido violado lo fuerzan, paradójicamente, a rechazar esa misma comunidad y a abandonar el propio código, deja de querer sobresalir y ostentar тıи́ en la batalla, de este modo pasa de héroe a antihéroe. Luego se revierte la postura a partir de la muerte de su amigo. ${ }^{24}$

En el canto A, el plano humano entre Aquiles y Agamenón tiene su personaje moderador en Néstor; el correlato conciliador en el plano divino entre Zeus y Hera se ve en Hefesto. Así como Hefesto forja el hierro, Néstor forja voluntades entre los semejantes. En la tragedia, Antígona intenta persuadir de modo de conservar las pautas de la humanidad, e insiste en el poder de mágico encantamiento trasmitido por el ritmo sintagmático de las palabras. Néstor dice en el canto IX (63-64):

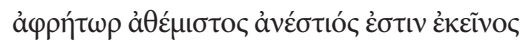

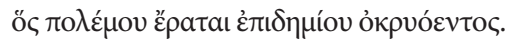

"Sin familia, sin ley y sin hogar vive aquel quien ama la horrible guerra civil".

24 Cfr. Toohey (1992, p. 20-43). 
La raíz de la palaba àđéfı tov también tiene su presencia en el discurso de

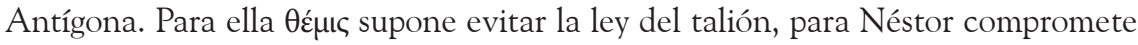
mantener la paz social.

La recurrencia del discurso que persuade por la dulzura del lenguaje reaparece en el canto IX, cuando el anciano aconseja apaciguar la cólera de Aquiles con palabras melifluas y agradables y, además, con bienes materiales. En esa ocasión, Agamenón resuelve el traspaso de esas ofrendas; el Atrida se ocupa del aspecto material de las súplicas que se dividen, a su vez, en dos clases. Los primeros conforman el grupo de los bienes que serán entregados en lo inmediato, como la devolución de Briseida sin haberla poseído nunca. Otros bienes serán obtenidos cuando tomen Troya, y entregados a Aquiles una vez que lleguen a la patria tierra. El resultado de esta embajada ha fracasado parcialmente. Si el poder de persuasión hubiera estado centrado en la palabra, quizás la respuesta hubiera sido otra.

\section{Conclusiones}

Antígona manifiesta una presencia decisiva en los dos Prólogos que quedan establecidos a partir de la división de la obra en sendas partes. En el Episodio I se acerca Ismene que advierte la llegada de Creonte en el Segundo; y, en el Episodio IV, se acerca Polinices, anunciado por Teseo y Antígona.

El principio ético de $\varphi \lambda \lambda i ́ a$ requiere de reciprocidad. La conducta de Antígona apela a ese pedido expreso. Los conceptos de preservación, beneficio y favor impregnan su discurso, además de representar el concepto de $\varphi$ i $\lambda$ ía en sus tres aspectos: ya sea como perteneciente al mismo génos, como ciudadana y, por último, como amiga.

El punto culminante en cuanto a ausencia de $\varphi$ i $\lambda i ́ a$ en la obra se halla en el Estásimo III, el pesimismo de los ancianos sometidos a la triste vejez pone el acento en la soledad y falta de reciprocidad de los viejos.

Tanto Antígona como el anciano Néstor propician el diálogo sincero, proclaman deponer las mezquindades personales en pos del bien común. Ellos están convencidos de que la voz humana prevalece como el único medio que puede salvar a los hombres en las situaciones decisivas. Sus voces pasan aparentemente desapercibidas, en buena medida porque el centro del interés se posa en los debates entre los personajes que confrontan: Edipo frente a Creonte y Polinices y, en la épica, Agamenón enemistado con Aquiles. 
La segunda parte de la obra presenta al personaje de Antígona como una heroína sofoclea: plena de contenido decide sus propios actos, aunque el resultado de esos procesos permanece desconocido para ella y no puede dominarlo.

El Éxodo se une directamente al Prólogo por la presencia de Edipo en su aspecto de clara reivindicación mito-histórica, para él y para Atenas y, en esa instancia definitiva, la presencia de Teseo se destaca crucial. El rey de Atenas se enaltece como el único hombre capaz de estar presente frente al milagro y mirar hacia el futuro promisorio, con esa protección metafísica que ofrece Edipo. Las hijas, en cambio, se marchan al espacio mítico del encuentro con los hermanos, para morir -Antígona- un día después.

En cuanto al regreso, la obra guarda relación con Odisea, ${ }^{25}$ pero el personaje de Antígona en Edipo en Colono nos recuerda la conducta responsable y afectiva de Néstor en Ilíada, el héroe de bajo perfil que orienta la acción sin que esto moleste a los jefes.

En su obra homónima, Antígona representa el canon aquileo del héroe: temperamental, sólida en sus convicciones, poderosa en su resistencia física -paradójicamente- y atraída irresistiblemente por la muerte en la juventud, de carácter altanero para la defensa de sus ideales y cálida para el apoyo incondicional a los seres amados.

En la última obra del autor trágico, la experiencia de la joven, con sacrificios prolongados en el tiempo, forja una personalidad cuya sabiduría puede ser asimilada a los ancianos épicos como Néstor.

\section{BiBLIOGRAFÍA CITADA}

Araujo, María y Marías, Julián (eds.) Aristóteles. Ética a Nicómaco, Madrid: Centro de Estudios Constitucionales, $1985^{4}$.

Belfiore, Elizabeth S. Murder Among Friends. Violation of Philia in Greek Tragedy, New York-Oxford: Oxford University Press, 2000.

Benavente Barreda, Mariano. Sófocles. Tragedias y Fragmentos, Madrid, Ediciones Clásicas, 1999.

25 De este tema nos hemos ocupado en Argos 2010, p. 97-111. 
Blundell, Mary Whitlock. Helping Friends and Harming Enemies, Cambridge: Cambridge University Press, 1991.

CAmpbell, Lewis. (ed.) Sophocles. The plays and fragments, Vol 1 y 2, Oxford: At the Clarendon Press, 1879 y 1881.

CAirns, Douglas L. Aidós. The Psychology and Ethics of Honour and Shame in Ancient Greek Literature, Oxford: At the Clarendon Press, 1993.

Dain, Alphonse y Mazon, Paul. (ed.) Sophocle. T. III, Paris: Les Belles Lettres, 1974.

Di Benedetto, Vincenzo. Sofocle, Firenze: La nuova Italia Editrice, 1988.

EDMunds, Lowell. "Cults and the Legend of Oedipus", Harvard Studies in Classical Philology. Vol. 85, Harvard: Harvard University, 1981, p. 221-238.

Edmunds, Lowell. Theatrical Space and Historical Place in Sophocles' Oedipus at Colonus, Boston, 1996.

ERreCAlde, Alejandro Martín "Ilíada XXII, 98-130: El soliloquio de Héctor o la definición discursiva del "héroe del aidós", Argos 24/2000, Buenos Aires, p. 41-52.

Ferrater Mora, José. Diccionario de Filosofía, Buenos Aires, Madrid: Alianza, 1992.

Griffin, Jasper. (ed) Sophocles Revisited. Essays presented to Sir Hugh Lloyd-Jones, Oxford: Oxford University Press, 1999.

Hutchinson, G. O. "Sophocles and Time", en Griffin, J. (ed) Sophocles Revisited. Essays presented to Sir Hugh Lloyd-Jones, Oxford: Oxford University Press, 1999, p. 47-72.

JebB, Richard. (ed.) Sophocles, Oedipus Coloneus, Amsterdam, Brill, 1899.

Liddell-Scott. A Greek English Lexicon, Oxford, At the Clarendon Press, $1968^{9}$.

Monro, David y Allen, Thomas. Homeri Opera, T. I y II, Oxford: Oxford University Press, 1920.

Pearson, A. C. (ed.) Sophoclis, Fabulae, Oxford: Oxford University Press, 1928.

Romilly, Jacqueline de. Actualité de la Démocretie Athenienne, Paris: Bourin Editeur, 2006.

Saravia De Grossi, María Inés. "El discurso de Polinices (vv. 1284-1345) en Edipo en Colono de Sófocles", Synthesis № 9. 2002, p. 53-69.

Saravia de Grossi, María Inés. "Repertorio del campo semántico de la moralidad en Áyax de Sófocles", Anales de Estudios Clásicos y Medievales, en Actas de las II Jornadas Internacionales de Estudios Clásicos y Medievales. "El mundo clásico y medieval: antecedentes y proyecciones". http://investigadores.uncoma.edu.ar/cecym/iij2004. 
Saravia de Grossi, María Inés. "Los espacios en Edipo en Colono: el segundo estásimo", Classica v. 17/18, Sâo Paulo, 2004/5, p. 119-129.

Saravia de Grossi, María Inés. "La trasgresión de los límites en los héroes de Sófocles”, Circe no 12, 2008 p. 167-182.

Saravia, María Inés. "La voz de los dioses en Edipo en Colono de Sófocles", Argos, 2010, p. 97-111.

SeAford, Richard. Reciprocity and Ritual, Oxford: Clarendon Press Oxford, 1994.

Toohey, Peter. Reading Epic. An Introduction to Ancient Narratives. London and New York, Routledge, 1992.

Abstract: Antigone personifies the voice of moderation that opposes to Creon and Polyneices. She represents the ethical principle of philia, which is defined in three different aspects. The first one, as the friendship or affinity bonds concerning to family ties. The second one is seen as the relationship with citizens, to whom we are supposed to have share interests. This attitude is closed to philanthropy. The last aspect is perhaps the one that most accurately interprets the modern concept of "friend". To conclude, the conciliatory character of Oedipus's young daughter reminds about some performances of the honorable old age in the Homeric epics.

Keywords: Sophocles, Oedipus Coloneus, Antigone, philia, linked concepts. 